\title{
Diabetes genes identified by genome-wide association studies are regulated in mice by nutritional factors in metabolically relevant tissues and by glucose concentrations in islets
}

Maggie M Ho ${ }^{1}$, Piriya Yoganathan ${ }^{1}$, Kwan Yi Chu' , Subashini Karunakaran ${ }^{1}$, James D Johnson ${ }^{1,2}$ and Susanne M Clee ${ }^{1 *}$

\begin{abstract}
Background: Genome-wide association studies (GWAS) have recently identified many new genetic variants associated with the development of type 2 diabetes. Many of these variants are in introns of known genes or between known genes, suggesting they affect the expression of these genes. The regulation of gene expression is often tissue and context dependent, for example occurring in response to dietary changes, hormone levels, or many other factors. Thus, to understand how these new genetic variants associated with diabetes risk may act, it is necessary to understand the regulation of their cognate genes.

Results: We identified fourteen type 2 diabetes-associated genes discovered by the first waves of GWAS for which there was little prior evidence of their potential role in diabetes (Adam30, Adamts9, Camk1d, Cdc123, Cdkal1, Cdkn2a, Cdkn2b, Ext2, Hhex, Ide, Jazf1, Lgr5, Thada and Tspan8). We examined their expression in metabolically relevant tissues including liver, adipose tissue, brain, and hypothalamus obtained from mice under fasted, nonfasted and high fat diet-fed conditions. In addition, we examined their expression in pancreatic islets from these mice cultured in low and high glucose. We found that the expression of Jazf1 was reduced by high fat feeding in liver, with similar tendencies in adipose tissue and the hypothalamus. Adamts9 expression was decreased in the hypothalamus of high fat fed mice. In contrast, the expression of Camk1d, Ext2, Jazf1 and Lgr5 were increased in the brain of non-fasted animals compared to fasted mice. Most notably, the expression levels of most of the genes were decreased in islets cultured in high glucose.

Conclusions: These data provide insight into the metabolic regulation of these new type 2 diabetes genes that will be important for determining how the GWAS variants affect gene expression and ultimately the development of type 2 diabetes.
\end{abstract}

Keywords: Type 2 diabetes, Gene expression, Genome-wide association, High fat diet, Feeding and fasting, Mice, Pancreatic islets, Glucotoxicity

\footnotetext{
* Correspondence: susanne.clee@ubc.ca

${ }^{1}$ Department of Cellular and Physiological Sciences, Life Sciences Institute,

University of British Columbia, Vancouver, Canada

Full list of author information is available at the end of the article
} 


\section{Background}

Nearly 350 million people world-wide are currently affected by diabetes, and the number of people with type 2 diabetes mellitus is increasing at an alarming rate [1]. Type 2 diabetes results when the $\beta$-cells of the pancreas are no longer capable of producing sufficient insulin to meet the body's demands. Thus $\beta$-cell dysfunction is a key component of type 2 diabetes pathology. Although the increased prevalence of obesity and resulting insulin resistance is contributing to the increased prevalence of type 2 diabetes, many obese individuals are insulin resistant but do not develop diabetes [2]. Genetic factors, many of which have been proposed to affect $\beta$-cell function, play an important role in determining an individual's risk within this context [3-6]. In a small number of individuals, type 2 diabetes is caused by rare single gene mutations, but for most individuals type 2 diabetes results from the combined effects of many common single-nucleotide polymorphisms (SNPs), each of which have a small effect on risk and likely interact with each other and with environmental and lifestyle factors [7].

Genome-wide association studies (GWAS) have recently revealed many novel SNPs associated with type 2 diabetes. These include SNPs located in the regions near TCF7L2, HHEX-IDE, EXT2, FTO, SLC30A8, IGF2BP2, $C D K A L 1$, and CDKN2A-CDKN2B [8-13]. A second phase of studies identified many additional variants, including those near JAZF1, TSPAN8-LGR5, THADA, ADAMTS9, NOTCH2-ADAM30, CDC123-CAMK1D, and KCNQ1 [14,15]. The two genes in which common variants were previously convincingly associated with type 2 diabetes, PPARG and KCNJ11, were also identified in these GWAS $[12,16,17]$. More recently, numerous other SNPs have been identified in additional GWAS and meta-analyses [18].

The association between variants in TCF7L2 and type 2 diabetes, which was identified initially in pre-GWAS studies, has been almost universally replicated and has the largest effect on diabetes risk $[19,20]$. This transcription factor is known to play a role in WNT signalling and pancreatic development [20]. Variation in FTO has been shown to influence risk of type 2 diabetes through its effects on promoting obesity [8]. Variation within $I D E$, the insulin degrading enzyme, has previously been associated with risk of type 2 diabetes in both humans and rats, although these findings were not consistently replicated [21-26]. SLC3OA8 is a zinc transporter expressed in $\beta$-cells and is known to be involved in insulin granule formation and insulin secretion [27-29]. IGF2BP2 encodes insulin like growth factor 2 mRNA binding protein 2 , which plays a role in RNA stability and localization and has been suggested to affect pancreatic development [30]. NOTCH2 is a transcription factor important for pancreatic development [31] and the Notch pathway plays a role in adult beta-cell survival [32]. KCNQ1 is a voltage-gated potassium channel that has been shown to affect insulin secretion [33]. However, the mechanisms by which the remainder of these genes affect diabetes risk are largely unknown. Thus, we sought to obtain evidence of their potential role in metabolic disease.

Most of the diabetes-associated SNPs were found in non-coding regions of the genome and are thus likely to affect gene regulation. In order to understand how these genes affect type 2 diabetes and how the SNPs associated with diabetes affect gene expression, we need to first understand the physiological processes that regulate the expression of these genes. We examined the expression patterns of these potential new diabetes-susceptibility genes to determine which are expressed in tissues important for the development of type 2 diabetes. This may also suggest the potential mechanism(s) by which alterations in these genes affect diabetes risk (e.g. insulin secretion versus insulin sensitivity). We also sought to determine whether any of these genes are regulated by conditions known to alter the expression of metabolically relevant genes. We examined the expression of these genes under fasting and non-fasting conditions (e.g. in response to insulin), which might be altered if they affect peripheral insulin sensitivity. Consumption of diets high in fats and sugars is associated with risk of developing type 2 diabetes [34] and many genes that are critical for $\beta$-cell function are regulated by glucose [35]. Thus, we also compared their expression in fasted mice consuming a normal chow diet or a diet high in fat and sugar, and examined the expression of these genes in mouse pancreatic islets cultured under low and high glucose concentrations. Here we show that most of the diabetesassociated genes are expressed in many metabolically relevant tissues and the expression levels of several of these genes were decreased by high fat feeding or were increased in the fed state in the brain. In addition, we found most of these genes are down-regulated by increased glucose concentrations in mouse islets.

\section{Results}

\section{Tissue distribution of gene expression}

High throughput gene expression profiling has previously been performed to identify gene expression patterns across a wide variety of tissues [36], but such microarray-based data must be complemented by accurate and quantitative analysis. Thus, we performed qPCR analysis of the recently identified diabetes susceptibility genes across a panel of tissues (Table 1) to determine their relative expression levels in each tissue. Most of these genes were expressed in many metabolically relevant tissues including pancreatic islets, liver, white and 
Table 1 Relative expression patterns of GWAS diabetes genes in chow fed mice

\begin{tabular}{|c|c|c|c|c|c|c|c|c|c|c|c|c|c|c|c|c|c|}
\hline & $|s|$ & Brain & Hypo & P-AT & BAT & Liver & SkM & Hrt & St & SI & LI & Lung & Kid & Spl & Ov & Ut & Thy \\
\hline Adam30 & $\mathrm{NE}$ & Low & NE & Avg & NE & $\mathrm{NE}$ & Avg & Avg & Avg & NE & $\mathrm{NE}$ & $\mathrm{NE}$ & $\mathrm{NE}$ & Avg & $\mathrm{NE}$ & NE & Avg \\
\hline Adamts9 & Low & Low & Avg & Avg & Avg & Avg & NE & Avg & Avg & NE & Avg & Avg & Avg & Avg & High & High & Avg \\
\hline Camkld & Avg & Avg & Avg & Avg & Avg & Avg & Low & Avg & Avg & $\mathrm{NE}$ & High & $\mathrm{NE}$ & Avg & Avg & Avg & Avg & $\mathrm{Hig}$ \\
\hline Cdc123 & Avg & Avg & Avg & Avg & Avg & Avg & Low & Avg & Avg & NE & Avg & Low & Avg & Avg & High & Avg & Avg \\
\hline Cdkal1 & Avg & Avg & Avg & Avg & Avg & Avg & Avg & Avg & Avg & Avg & Avg & Low & Avg & Avg & Avg & Avg & Avs \\
\hline Cdkn2a (Arf) & Avg & Avg & Avg & Avg & Avg & Avg & Avg & Avg & Avg & Avg & Avg & Avg & Avg & Avg & Avg & Avg & Avg \\
\hline Cdkn2a & $\mathrm{NE}$ & $\mathrm{NE}$ & $\mathrm{NE}$ & Avg & Avg & $\mathrm{NE}$ & $\mathrm{NE}$ & NE & $\mathrm{NE}$ & $\mathrm{NE}$ & Avg & $\mathrm{NE}$ & Avg & Avg & $N E$ & NE & Lov \\
\hline$C d k n 2 b$ & High & Avg & Avg & Avg & Avg & Avg & NT & Avg & NT & High & NT & NT & Avg & NT & High & Low & Lov \\
\hline Ext2 & Low & Avg & Avg & Avg & Avg & Avg & Low & Avg & Avg & Avg & Avg & Low & Avg & Avg & High & Avg & Avg \\
\hline Hhex & Low & Avg & Avg & Avg & Avg & High & Low & Avg & Low & Low & Avg & Low & Avg & High & Avg & High & Avs \\
\hline Ide & Avg & Avg & Avg & Avg & High & Avg & NT & Avg & NT & Avg & NT & NT & NT & NT & High & Low & LoV \\
\hline Jazfi & Avg & Avg & Avg & Avg & High & $\mathrm{NE}$ & $\mathrm{NE}$ & Avg & Low & Low & Avg & Low & Low & Low & Avg & High & Av \\
\hline Lgr5 & $\mathrm{NE}$ & High & Avg & Avg & Low & Avg & Low & Avg & Avg & $\mathrm{NE}$ & Avg & Low & $\mathrm{NE}$ & Avg & High & High & Avc \\
\hline Thada & Avg & Avg & Avg & Avg & Avg & Avg & $\mathrm{NE}$ & Avg & Avg & $\mathrm{NE}$ & Avg & Low & Avg & Avg & High & Avg & Avg \\
\hline Tspan8 & Low & Low & Low & Avg & Avg & Low & Low & Avg & High & NE & High & NE & Avg & High & Avg & High & Lov \\
\hline
\end{tabular}

Expression levels are relative within a gene, but comparisons between genes cannot be made. Isl = islets, Hypo = hypothalamus, P-AT= parametrial white adipose tissue, BAT = brown adipose tissue, $\mathrm{SkM}=$ skeletal muscle (soleus), $\mathrm{Hrt}=$ heart, $\mathrm{St}=$ stomach, $\mathrm{SI}=$ small intestine (duodenum), $\mathrm{LI}=$ large intestine $(\mathrm{distal}), \mathrm{Kid}=$ kidney, $\mathrm{Spl}=$ spleen, Ov = ovary, Ut = uterus, Thy = thymus. $\mathrm{NE}=$ not expressed, Ct values within 2 cycles of negative control; avg. $=$ average expression (within 5 fold ( 2.3 cycles) of average expression across all tissues); high $=>5$ fold higher (Ct values $>2.3$ cycles lower) than average expression; low $=>5$ fold lower (Ct value $>2.3$ cycles higher) than average expression. NT $=$ not tested.

brown adipose tissue, skeletal muscle, and heart. In addition, most were expressed in the hypothalamus and in regions of the brain outside the hypothalamus. Few of these genes were robustly expressed in skeletal muscle or small intestine. We detected expression of all the genes in pancreatic islets except Adam30, $C d k n 2 a$, and Lgr5. Together, these studies point to several metabolically relevant tissues as potential key sites of action of the diabetes susceptibility genes identified by the GWAS.

\section{Regulation of GWAS diabetes genes by dietary status in the liver}

To determine whether these new type 2 diabetes susceptibility genes are regulated by nutritional manipulations, we examined whether there was a change in their expression between tissues from fasted and non-fasted chow-fed mice, or between tissues from fasted chow and fasted high fat diet-fed mice. We used a common control group (fasted, chow-fed mice) to which the nonfasted, chow-fed mice and the fasted, high fat diet-fed mice were compared. As the liver is a key metabolic organ and a major target of insulin action, we first examined the expression of these genes in the liver (Figure 1). The expression of Jazf1 was decreased by approximately $70 \%$ in mice fed a high fat diet compared to chow-fed controls. Similar differences were observed for Adamts9 (75\% decrease) and Hhex (60\% decrease). Whereas we could detect expression of the Arf isoform of $C d k n 2 a$ in chow-fed mice, its expression was detected in only 2 samples from the high fat diet-fed mice. In contrast to many classical transcriptional targets of insulin signalling, none of the genes examined in this study had significantly altered expression in the livers of fasted versus non-fasted mice. Again, while it was found in most of the liver samples from the chow-fed fasted control mice, the expression of $C d k n 2 a$ (Arf) was detected only sporadically in the livers of non-fasted mice. While $C d k n 2 b$ was expressed in all the samples, its expression did not differ between groups. No differences in

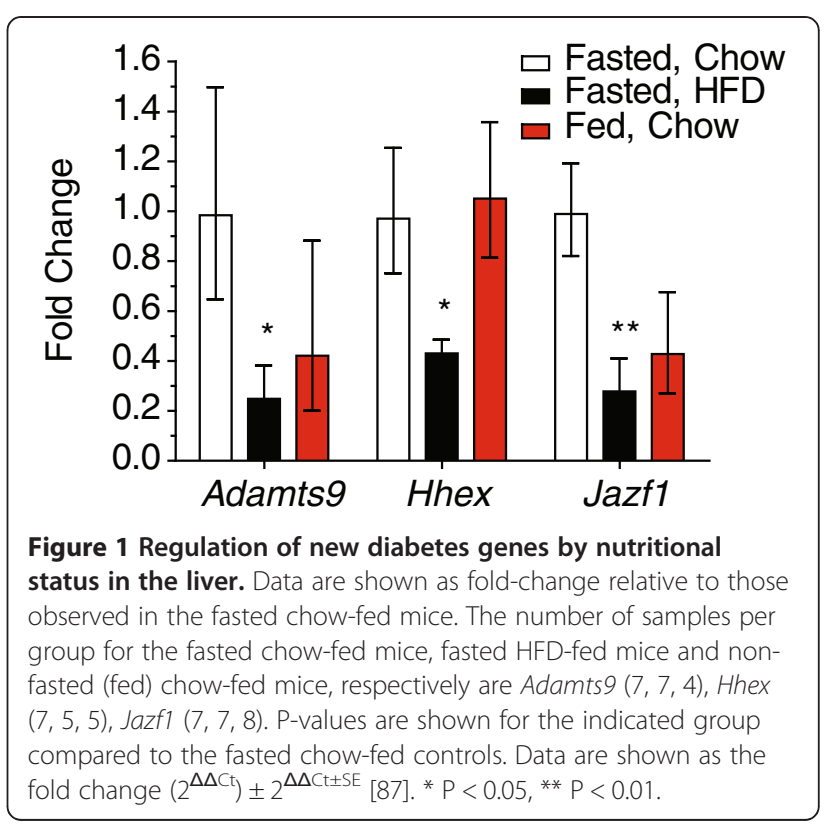


expression were observed for Camk1d, Cdc123, Cdkal1, Ext2, Ide, Lgr5, Thada, or Tspan8 (not shown), although expression of $C d c 123$ was decreased $~ 35 \%$ in high fat diet-fed mice $(P=0.07)$. Thus, while the hepatic expression of some of these new diabetes genes is regulated by chronic consumption of diets high in fat and sugar, we do not find evidence that they are acutely regulated in response to feeding and fasting as might be expected for key insulin-responsive genes.

\section{Regulation of GWAS diabetes genes by dietary status in adipose tissue}

Adipose tissue is a critical insulin-responsive tissue. Fat also produces many factors, adipokines, that may contribute to whole body insulin sensitivity. We examined whether any of these diabetes susceptibility genes are regulated by nutritional status in adipose tissue (Figure 2). $C d k n 2 b$ and Thada expression levels were decreased $\sim 50$ and $30 \%$, respectively, in fasted chow versus high fat diet-fed mice. Jazf1 expression may also be reduced ( $45 \%, \mathrm{P}=0.06$, not shown). In contrast Ide expression levels were $\sim 1.6$ fold higher in high fat-fed mice. The expression of Adam30 was decreased over $80 \%$ in fasted versus non-fasted mice, although this did not reach statistical significance $(P=0.06)$. None of the remaining genes expressed in adipose tissue showed significant changes in expression for either condition (Figure 2), suggesting little involvement of these new diabetes genes in adipose tissue function. This is in contrast to many of the newly identified obesity genes [37].

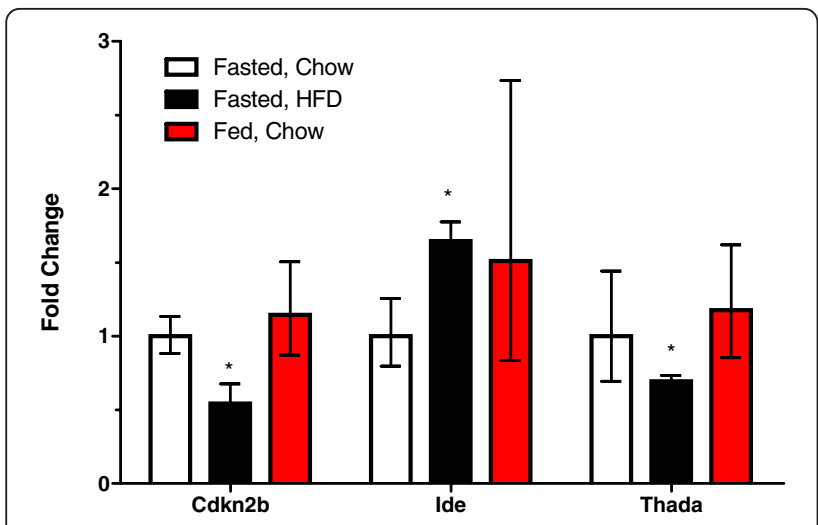

Figure 2 Regulation of new diabetes genes by nutritional status in adipose tissue. Data are shown as fold-change relative to those observed in the fasted chow-fed mice $(n=7$ for the fasted chow-fed group, 6 for the fasted HFD-fed mice and 8 for the fed chow-fed mice). P-values are for the comparison between the indicated group and the fasted, chow-fed control mice. Data are shown as the fold change $\left(2^{\Delta \Delta C \mathrm{t}}\right) \pm 2^{\Delta \Delta \mathrm{Ct} \pm \mathrm{SE}}[87] . *{ }^{*} \mathrm{P}<0.05$.

\section{Regulation of GWAS diabetes genes by dietary status in the brain}

Recent studies have shown important neuronal contributions to the regulation of metabolism, insulin sensitivity and islet function, particularly within regions of the hypothalamus [38-41]. Thus, we examined the expression of the recently identified type 2 diabetes susceptibility genes in the hypothalamus (Figure 3) and the remainder of the brain (Figure 4). In the hypothalamus, the expression of Adamts 9 and Camk1d were decreased by $~ 80 \%$, in fasted chow versus fasted high fat diet-fed mice (Figure 3 ). $C d k n 2 b$ expression was similarly decreased, although this did not reach statistical significance (not shown). The mRNA levels of Jazf1 and Thada were 60-70\% lower in the high fat diet-fed mice. $\operatorname{Lgr} 5$ also tended to be decreased (not shown). In fasted versus non-fasted chowfed mice, Cdkal1 expression was decreased by approximately $50 \%$ (Figure 3 ). No significant differences were found for Cdc123, the Arf isoform of Cdkn2a, Ext2, Hhex, Ide, Lgr5, or Tspan8.

In the remainder of the brain outside the hypothalamus none of the genes were significantly affected by the consumption of the high fat diet, but strikingly many of them were regulated by feeding/fasting status (Figure 4). Cdkn2b expression was increased $\sim 3$-fold by both conditions, but neither reached statistical significance. Only four genes expressed in the brain, Cdc123, Cdkal1, Ide, and Thada, were not affected by either experimental condition. Camk1d expression was increased over 7 -fold in non-fasted versus fasted chow-fed mice. Jazf1 and Lgr5 expression were increased 3.5 and 4.5fold, respectively, in non-fasted mice. Ext2 and Hhex had a 2 to 2.5 -fold increase in expression in fasted versus non-fasted mice. Tspan 8 on the other hand, had a significant $60 \%$ decrease in expression in non-fasted versus fasted mice. Like in the liver, the expression of the Arf isoform of Cdkn2a was low but detectable in both chow-fed groups, but not in the mice consuming the high fat diet. Adam30 expression was only detected in the brains of non-fasted chow-fed mice. Together, these results illustrate that the expression of several type 2 diabetes susceptibility genes can be metabolically regulated in the brain and point to the potential importance of neuronal function in type 2 diabetes susceptibility.

\section{Regulation of GWAS diabetes genes by glucose in pancreatic islets}

Many of the recently discovered type 2 diabetes genes have been suggested to affect the development and/or function of pancreatic islets [6]. The function, growth and survival of $\beta$-cells can be regulated acutely and chronically by glucose [34]. Thus, we examined whether the new type 2 diabetes susceptibility genes are regulated by overnight incubation in low $(5 \mathrm{mM})$ or high $(25 \mathrm{mM})$ 


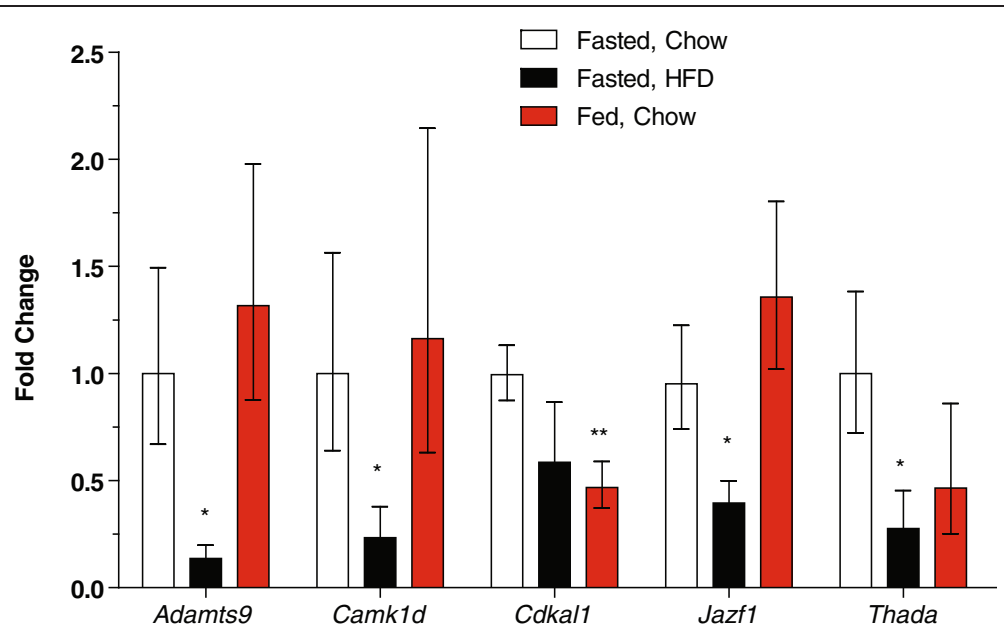

Figure 3 Regulation of new diabetes genes by nutritional status in the hypothalamus. Data are shown as fold-change relative to those observed in the fasted chow-fed mice. The number of samples per group for the fasted chow-fed mice, fasted HFD-fed mice and non-fasted (fed) chow-fed mice, respectively are Adamts9 $(7,5,4)$, Camk1d (7, 5, 5), Cdkal1 $(10,5,9)$, Jazf1 $(10,8,7)$, Thada $(7,5,5)$. P-values are shown for the indicated group compared to the fasted chow-fed controls. Data are shown as the fold change $\left(2^{\Delta \Delta C t}\right) \pm 2^{\Delta \Delta C t \pm S E}[87] .{ }^{*} P<0.05$, ** $P<0.01$.

glucose (Figure 5). Most genes were significantly or tended to be downregulated under conditions of high glucose. Cdkal1, Cdkn2a (Arf, $\mathrm{P}=0.07)$, Ide, Jazf1, Camk1d, and Tspan8 $(\mathrm{P}=0.06)$ expression levels were decreased $\sim 50-60 \%$. Meanwhile, the expression of Cdkn2b, Hhex $(\mathrm{P}=0.10)$, Cdc123, Adamts9 $(\mathrm{P}=0.09)$, and Thada were reduced $30-40 \%$. To ensure the islets incubated in high glucose did not have globally decreased expression, we examined the expression of
Txnip, which has been shown to be highly upregulated by glucose [35] and found that its expression was still significantly elevated in the islets cultured in high glucose (Figure 5). Mouse islets consist of $\beta$-cells and other cell types. Thus, the MIN6 $\beta$-cell line was also examined. We found that all the genes were expressed in this cell line (not shown), although this does not preclude that they also are expressed in other cell types within the islet.

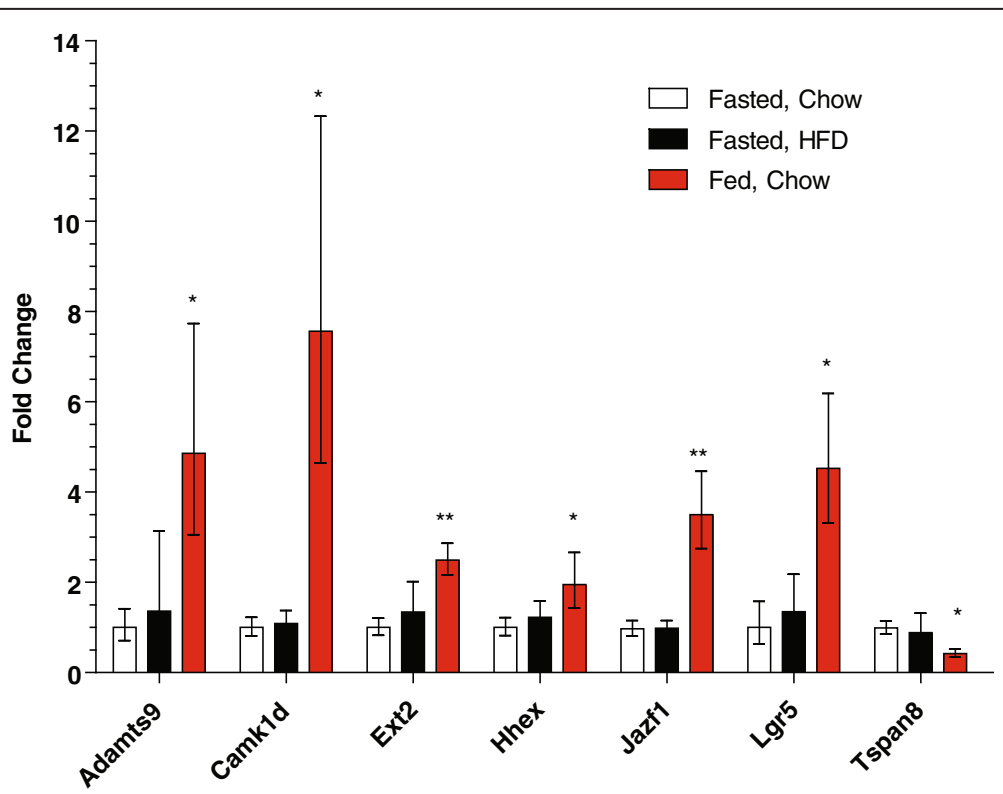

Figure 4 Regulation of new diabetes genes by nutritional status in the remainder of the brain. Data are shown as fold-change relative to those observed in the fasted chow-fed mice. HFD = high fat diet. The number of samples per group for the fasted chow-fed mice, fasted HFD-fed mice and non-fasted (fed) chow-fed mice, respectively are $(6,5,10)$ except for Adamts $9(6,4,10)$. P-values are shown for the indicated group compared to the fasted chow-fed controls. Data are shown as the fold change $\left(2^{\Delta \Delta c t}\right) \pm 2^{\Delta \Delta C t \pm S E}[87]$. ${ }^{*} P<0.05$, ** $P<0.01$. 


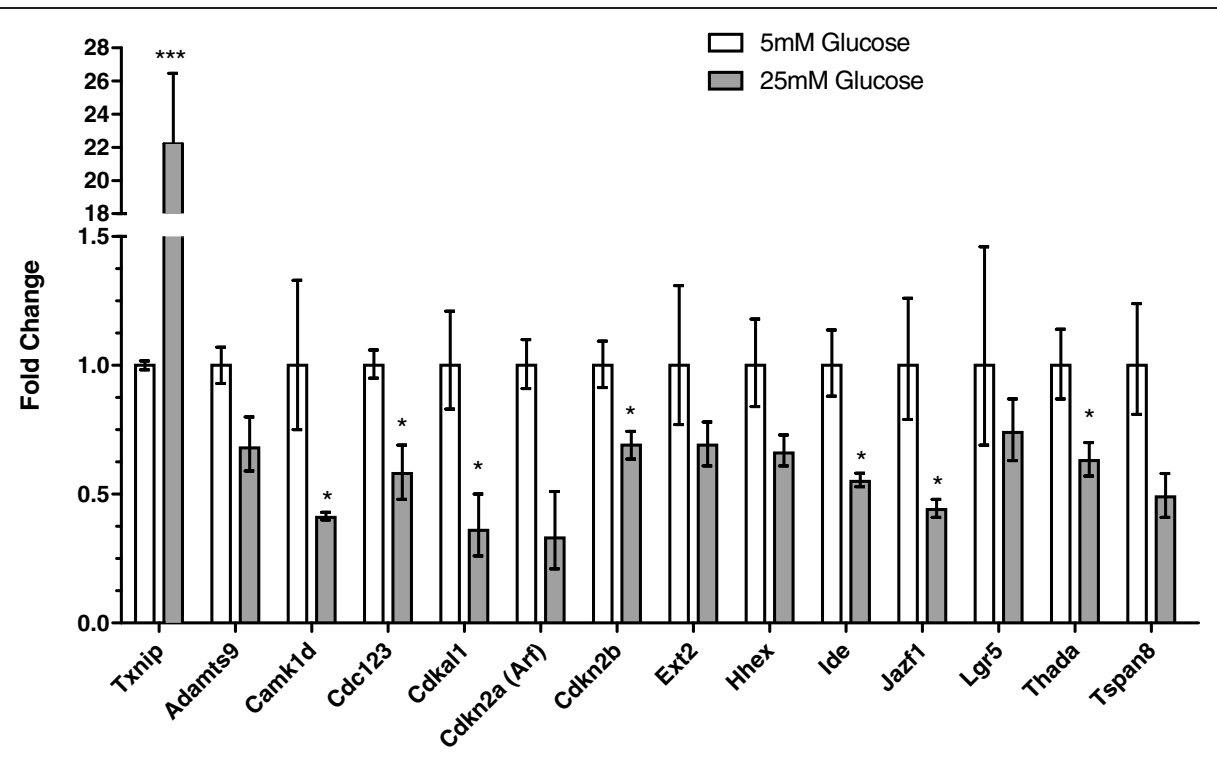

Figure 5 Regulation of new diabetes genes by glucose levels in pancreatic islets. Data are shown as fold-change, $\left(2^{\Delta \Delta C t}\right) \pm 2^{\Delta \Delta C t \pm S E}[87]$, relative to those observed in the islets incubated in low $(5 \mathrm{mM})$ glucose. Each group is the average of three replicates, each of which was comprised of pooled islets from two mice. ${ }^{*} P<0.05,{ }^{* *} P<0.001$.

\section{Discussion}

The goal of the present study was to understand whether metabolic factors affect the expression of the genes recently implicated in the development of type 2 diabetes for which there was little prior evidence of their potential role(s) in this disease. Although many additional SNPs have been identified in subsequent GWAS and meta-analyses [18], we focussed these studies on the genes identified in the first waves of GWAS, as these have been the subject of most follow-up studies to date. Specifically, we examined acute changes in expression of these genes in response to feeding and fasting and longer term changes in the expression of these genes in response to a diet high in fat and sugar, recognized as a critical environmental risk factor for type 2 diabetes.

It has been hypothesized that most of the new genetic variants affect $\beta$-cell function, development or survival but not insulin sensitivity [6]. Consistent with this, we found all of the genes except Adam30 and Cdkn2a were expressed in pancreatic islets. These genes were expressed, however in the transformed $\beta$-cell line, MIN6. The expression of all the genes except $\operatorname{Lgr} 5$ decreased following incubation of the islets in high glucose concentrations. It can thus be hypothesized that these genes may normally play a beneficial role in islet function, and a reduction in the expression of these genes could contribute to glucotoxic $\beta$-cell dysfunction or survival. However, we also found evidence that most of the genes could have potential roles in other metabolically-relevant tissues. Genes affecting insulin sensitivity may be expected to be expressed in peripheral insulin sensitive tissues, such as liver and adipose tissue, and be responsive to metabolic status. Consumption of a high fat diet was associated with a tendency for the expression of several of these genes to be decreased. Similarly, many of the genes were regulated by feeding and fasting. Only the two splice isoforms of $C d k n 2 a$ had no evidence of metabolic regulation in any of the other tissues examined.

Jazf1, also known as Tip27, encodes a transcriptional repressor of $\mathrm{Nr} 2 \mathrm{c} 2$, an orphan nuclear receptor of the steroid receptor family also known as TR4 and TAK1. $\mathrm{Nr} 2 \mathrm{c} 2$ has been reported to modulate apoptosis $[42,43]$ and its loss in mice is associated with reduced mitochondrial function and increased oxidative stress, and conversely with reduced adipose tissue inflammation, hepatic steatosis and insulin resistance [44-46]. Jazf1mediated alterations in Nr2c2 could thus affect both insulin sensitivity and $\beta$-cell function. Genetic variation in Jazf1 has been variably associated with measures of insulin sensitivity and $\beta$-cell function [47-52], and our expression data support roles for this gene in both. Jazf1 was expressed in nearly all tissues examined and its expression in islets was decreased following culture in high glucose-containing media. Consistent with a pathogenic role in islets, it has recently been shown that JAZF1 expression is reduced in individuals with type 2 diabetes or hyperglycemia, and that JAZF1 expression was correlated with insulin secretion [53]. However, our findings suggest the reduced expression may be a consequence of their hyperglycemia, not the underlying cause. These data are consistent, however, with a role of Jazf1 in 
further accelerating $\beta$-cell dysfunction once individuals develop hyperglycemia or perhaps impaired glucose tolerance. Jazf1 expression in the liver and hypothalamus was decreased in mice fed the high fat diet, with the same tendency in adipose tissue. The GWAS SNPs may affect the expression of Jazf1 in adipose tissue, suggesting that its function in this tissue may be important for its role in type 2 diabetes [54]. That we also observed changes in the expression of Jazf1 in the brain and hypothalamus, suggests further potentially important sites of action.

Adamts 9 is an anti-angiogenic factor known to be expressed in vascular endothelial cells [55] and is implicated in endoplasmic reticulum to Golgi transport [56]. Although some studies have found associations between SNPs in this gene and various measures of insulin sensitivity or secretion $[49,50]$, many others have not $[47,48,52,57]$. Microvascular structure affects both insulin secretion and sensitivity [58]. Adamts9 expression tended to be downregulated by high glucose in islets and was decreased in the hypothalamus and liver of high fat diet-fed mice. These data suggest that this gene may play a role in the neural regulation of metabolism in addition to having effects, perhaps on insulin sensitivity, in the liver and also in islets that may be related to its role in vascularization [59].

Hhex encodes a homeobox transcription factor known to be involved in pancreatic and liver development [60,61]. SNPs in HHEX have been associated with decreased insulin secretion perhaps due to alterations in vesicle docking [57,62-66]. Most studies have failed to find associations between HHEX SNPs and insulin sensitivity [52,57,62-64,67], although associations with insulin clearance and hepatic insulin sensitivity have been reported [52,64]. We found Hhex to be expressed in several tissues besides the pancreas, with evidence of decreased expression in the liver in response to high fat feeding and increased expression in the brain in nonfasted mice. These findings provide potential support for roles of Hhex in metabolism outside the pancreas. The GWAS SNPs associated with type 2 diabetes are located between Hhex and Ide. There was prior evidence for a role of Ide in type 2 diabetes [21,22,25,26]. We found Ide expression to be increased by high fat feeding in adipose tissue and to be decreased by the incubation of islets in high glucose, consistent with a role of Ide in $\beta$-cell function [63]. Combined, these data suggest potential roles for both Hhex and Ide in type 2 diabetes susceptibility.

Little is known about the potential roles of Thada in metabolic disease. It is a gene associated with a common chromosomal breakpoint in thyroid cancers, that may affect cell death receptors [68]. We found widespread expression of Thada and noted its decreased expression in islets following culture in high glucose. Thada expression was also reduced in response to high fat feeding in both adipose tissue and the hypothalamus. No evidence for association of SNPs in this gene with insulin sensitivity have been found $[48,49,52,57]$, and while most studies have not found associations with insulin secretion [47-49,57], an association with reduced insulin secretion in response to non-nutrient secretagogues and potentially $\beta$-cell mass has been reported [50]. Our data are consistent with a primary role of this gene in the pancreas in determining type 2 diabetes susceptibility, although indicate it may also have effects on the regulation of energy balance and metabolism.

Although Adam30 (A disintegrin and matrix metalloprotease 30) has been reported to be expressed only in the testis [69], we found evidence of expression in several metabolically relevant tissues including the brain, adipose tissue, heart and stomach. It was not expressed in islets. We observed a marked reduction of its expression in adipose tissue collected from non-fasting animals, providing a potential site of action whereby this gene may affect metabolism and thus type 2 diabetes risk.

In contrast to the above genes, the expression of other genes were not widely altered aside from within pancreatic islets, consistent with the primary mechanism by which they are associated with diabetes being through alterations in islet biology. The mechanisms by which SNPs at the CAMK1D-CDC123 locus affect diabetes susceptibility are unknown, and it is unclear which of these two genes is affected by the causative genetic variation. Some, but not all, studies have found associations of SNPs at this locus with insulin secretion, while no associations with insulin sensitivity have been found [47-50,52,57]. There is evidence that genetic variation near CAMK1D can affect its expression, at least in lymphocytes [54]. The expression of both genes was similarly reduced in islets cultured in high glucose, suggesting the possibility that they are under common regulatory control in these cells. We found decreased expression of Camk1d in the hypothalamus of high fat-fed mice and increased expression in other regions of the brain in non-fasted mice, suggesting it may affect the neuronal control of metabolism or islet function. In contrast, no substantial changes in Cdc123 expression in response to feeding and fasting or high fat diet consumption were observed. As the SNPs at this locus are primarily associated with insulin secretion and the expression of both genes in islets was altered, these data cannot distinguish which may be the causative gene.

SNPs within CDKAL1 have been associated with insulin secretion and not insulin sensitivity $[13,47,52,57,63,66,67,70]$. Cdkal1 is a tRNA modification enzyme. Specifically, this protein is a methylthiotransferase that modifies tRNA ${ }^{\text {Lys }}$, stabilizing interactions between the tRNA and mRNA, decreasing misreading of its cognate codon [70]. Mice deficient in Cdkal1 have impaired glucose tolerance and insulin secretion, and 
evidence of $\beta$-cell ER stress [71,72]. We found that Cdkal1 expression in pancreatic islets was decreased following incubation in high glucose, which could contribute to $\beta$-cell dysfunction in settings of hyperglycemia. Interestingly, we also found that Cdkal1 expression was reduced in the fed state in the hypothalamus, suggesting it may have metabolic functions in addition to those in insulin synthesis and secretion.

The GWAS have identified SNPs at the $C d k n 2 a-C d k n 2 b$ locus. The $C d k n 2 a$ (cyclin dependent kinase inhibitor 2a) gene has two alternative splice isoforms that encode distinct proteins, Cdkn2a and Arf. The Arf isoform is generated by the use of an upstream alternative first exon. Both are involved in cell cycle control. We found expression of the Arf isoform to be very low in chow-fed mice and not detectable in most tissues from high fat diet-fed mice. We found higher levels of expression of this gene in islets, and potential downregulation of its expression by high glucose concentrations. In contrast, the Cdkn2a isoform was found in a limited number of tissues and not in islets. These data suggest that Arf might be the relevant isoform of Cdkn2a, affecting diabetes by affecting $\beta$-cell mass. Given the loss of expression of this gene in high fat diet-fed mice it is tempting to speculate that this may be a mechanism affecting high fat diet-induced metabolic dysfunction. The expression of $C d k n 2 b$ was decreased in adipose tissue of high fat-fed mice. As this gene encodes a cell cycle inhibitor, this reduced expression may reflect increased proliferation of adipocyte precursors or perhaps infiltrating inflammatory cells. Interestingly, $C d k n 2 b$ expression was also decreased in islets incubated in high glucose, consistent with a role in the regulation of $\beta$-cell mass and glucose-induced $\beta$-cell proliferation [73]. Thus, as with the Hhex-Ide locus, these studies cannot distinguish whether $C d k n 2 a$ or $C d k n 2 b$ is the causative gene, and actually suggest a role for both in the development of type 2 diabetes.

Ext2 is a glycosyltranferase involved in the synthesis of heparin sulphate, and mutations in this gene are associated with abnormal bone growths (exostoses) [74]. This gene may also be involved in neural development [75]. The association between SNPs in this gene and type 2 diabetes has not been as well replicated $[10,12,13,62]$. We found increased expression of this gene in brain, suggesting a possible site of action as to where this gene could affect diabetes risk.

Lgr5 is a seven transmembrane receptor and a member of the rhodopsin family [76]. It is a marker of mitotically active intestinal stem cells and potentiates Wnt/ $\beta$-catenin signalling $[76,77]$. This is the only gene for which we did not find a significant decrease in expression in islets cultured in high glucose, although this certainly does not preclude it from having a role in pancreatic and $\beta$-cell development. Its expression was increased in the brains of non-fasted mice, suggesting another potential site of action through which it may mediate type 2 diabetes susceptibility.

Tspan8, also known as Co-029, is a cell surface protein implicated in pancreatic, colon and liver tumors and their metastasis, possibly through interaction with integrins [78]. Although some studies have found associations between SNPs in this gene and insulin sensitivity or secretion $[47,57]$, others have not [48-50,52]. Loss of this gene is associated with decreased body weight, although there were no detectable effects on glucose tolerance or insulin sensitivity [79]. In contrast to that study which did not detect expression of this gene in mouse pancreas [79], we found expression of this gene in isolated pancreatic islets and suggested regulation of its expression by glucose. Tspan 8 expression was significantly decreased in brains of fed compared to fasted chow-fed mice, suggesting it may also have a role in the neural control of metabolism.

In summary, we have identified nutritional regulation of many of the newly found type 2 diabetes-associated genes. As these studies were performed with a relatively small number of samples, it should be noted that smaller changes in expression may also exist that we had insufficient power to detect. These data provide support for the involvement of these newly identified type 2 diabetes susceptibility genes in $\beta$-cell function and also suggest potential roles for many of them in peripheral tissues, notably in the brain and hypothalamus, highlighting the potential importance of neuronal regulation of metabolism and islet function to type 2 diabetes [38-41]. Our study also highlights the tissue-specific regulation of these genes (changes in one or more tissues where the gene is expressed but not in all tissues), suggesting that the SNPs identified in the GWAS studies may need to be examined in the appropriate tissues and under several metabolic contexts [37]. Indeed, recent studies aimed at identifying genetic variants that affect gene expression (eQTLs) have found varying effects of these SNPs on gene expression in different tissues, particularly for SNPs located within not between genes, and notably that the SNPs were more associated with expression of diabetesassociated genes in metabolically relevant tissues such as liver, adipose and muscle than in lymphocytes, which are sometimes used as a surrogate because they are easily accessible [80-82]. The abundant regulation of these genes by nutritional status found in our study also suggests there are likely gene-diet interactions involving these SNPs [83] that may be a complicating factor in future human studies to assess the functional implications of the associated SNPs.

\section{Conclusions}

As SNPs may affect the regulation of genes up to $1 \mathrm{Mb}$ away [84], future studies should examine the regulation 
of other genes in the region of the associated SNPs to identify other possible candidates. Future studies should also examine the regulation of the remaining newly discovered type 2 diabetes-associated genes and their neighbours. Studies to discover how the type 2 diabetesassociated GWAS SNPs affect the regulation of nearby genes to promote diabetes will be important to realize the value of the GWAS studies, however our findings suggest that such studies will need to be carried out in the appropriate tissues and under controlled environmental conditions.

\section{Methods}

\section{Animals}

Female C57BL/6 J mice were housed in an environmentally controlled facility with 14 hour light cycles (7 am $9 \mathrm{pm}$ ) with unlimited water and were fed either a standard rodent chow (LabDiet 5010, Jamieson's Pet Food Distributors, Delta, BC, Canada) or a diet containing 60\% calories from fat (primarily lard) and 20\% calories from sugar (sucrose and maltodextrin; D12492, Research Diets, New Brunswick, NJ) from weaning. Mice were sacrificed at 8 weeks of age by $\mathrm{CO}_{2}$ asphyxiation. Mice were sacrificed either after a physiological 4 hour fast (9 am $1 \mathrm{pm})$ or at 9 am without fasting, as indicated. Tissues were rapidly collected and flash frozen in liquid nitrogen. All procedures were approved by the UBC Committee on Animal Care and were performed according to Canadian Council on Animal Care guidelines.

\section{Pancreatic islet isolation}

Islets were isolated from chow-fed female C57BL/6 J mice by collagenase digestion, using previously described modifications [32] of the filtration method reported by Salvalaggio et al. [85]. We handpicked islets into dishes of RPMI media (Invitrogen, Burlington, ON, Canada) containing either $5 \mathrm{mM}$ glucose or $25 \mathrm{mM}$ glucose. Although the mice were not fasted prior to islet isolation, the islets were incubated in these conditions overnight at $37^{\circ} \mathrm{C}$ and $5 \% \mathrm{CO}_{2}$ prior to RNA isolation. Experiments were performed in triplicate; each replicate comprised of 50 islets from each of 2 mice, for a total of 100 islets per replicate.

\section{Measurement of gene expression}

RNA extraction and cDNA synthesis were performed as described [37]. Primers were designed for all the genes from the first waves of type 2 diabetes GWAS for which there was no other evidence of their potential role in type 2 diabetes. Primers were designed to span an intron and to be located in exons common to all isoforms for any genes with alternatively spliced forms, except for $C d k n 2 a$ which has two well characterized isoforms, Arf and $C d k n 2 a$, for which specific primers were generated.
The primer sequences used for each gene are provided in Additional file 1: Table S1. Because these studies were performed over a span of several months, and in conjunction with other studies [37], the sample numbers varied between genes (e.g. due to the addition of new samples or when samples were completely used).

Gene expression was assessed by real-time quantitative reverse transcription PCR (qPCR) using SYBR Green Ibased detection (PerfeCTa SYBR Green FastMix, Quanta Biosciences, Gaithersburg, MD), as previously described [37]. We confirmed that only a single product was amplified from all samples through melt-curve analysis in addition to the direct visualization of PCR amplification products on an agarose gel prior to real-time analysis. Gapdh was selected as the reference gene as its expression was more consistent than $\beta$-actin (Actb), Cyclophilin (Ppib), Arbp, and 18S RNA across the different experimental conditions and tissues.

Delta $\mathrm{Ct}(\Delta \mathrm{Ct})$ values were calculated by subtracting the cycle threshold $(\mathrm{Ct})$ value for each gene from the $\mathrm{Ct}$ value of the control gene amplified contemporaneously. Delta delta $\mathrm{Ct}(\Delta \Delta \mathrm{Ct})$ values for each sample were calculated by subtracting the $\Delta \mathrm{Ct}$ of each sample from the average $\Delta \mathrm{Ct}$ of the fasted mice consuming chow (control) group or the islets incubated in $5 \mathrm{mM}$ glucose. For each gene, negative controls included both a no reverse transcriptase (no RT) and no template control (water).

For the tissue distribution, genes were considered expressed if the $\mathrm{Ct}$ value was at least 2 cycles lower (i.e. higher expression) than the lowest value in the negative controls, which was typically undetected. To examine the relative expression levels of each gene across the tissues in which it is expressed, we calculated the average $\mathrm{Ct}$ value for all the tissues that each gene is expressed in. Tissues with at least a 5-fold higher ( 2.3 cycles lower) expression than the average across tissues are shown as relatively "high" expression of that gene, while tissues where expression was more than 5-fold lower (Ct values > 2.3 cycles higher) than the average are indicated as having relatively "low" expression of that gene. For each gene, these calculations permit the comparisons of the same gene between tissues, however due to likely variation in primer efficiency, comparisons cannot be made between genes.

\section{Statistical analysis}

The study was comprised of three groups: two experimental groups (non-fasted chow-fed and fasted high fat diet-fed) each compared to a single control group (fasted chow-fed). Changes in gene expression within liver, adipose tissue, brain and hypothalamus, were compared using non-parametric Mann-Whitney U-tests for each of the experimental groups compared to the controls 
because of the small sample sizes [37]. This approach was chosen over the Kruskal-Wallis test because the comparison between the fasted high fat diet-fed and non-fasted chow-fed mice was not meaningful, as both fasting and diet conditions differed between these two groups. Unadjusted P-values are presented [86]. Comparisons between islets incubated in low and high glucose were performed by Student's $t$-test. Statistics were performed on the $\Delta \Delta \mathrm{Ct}$ values, prior to conversion to fold-change [37,87] using Prism (GraphPad Software). Data are shown as fold change, calculated as $2^{\Delta \Delta C t}$, with the upper and lower limits calculated as $2^{\Delta \Delta \mathrm{Ct} \pm \text { its standard error }}$, respectively [87].

\section{Additional file}

Additional file 1: Table S1. Primer sequences.

\section{Abbreviations}

Ct: Cycle threshold; GWAS: Genome-wide association; HFD: High fat diet; qPCR: Quantitative reverse transcription real time PCR; SNP: Single nucleotide polymorphism

\section{Competing interests}

The authors declare they have no competing interests.

\section{Authors' contributions}

MH, PY, KC and SK performed the experiments. SC conceived of and designed the study. $\mathrm{MH}$ and SC analyzed and interpreted the data. Some of the experiments were performed in the laboratory of JJ. All authors contributed to the writing of the manuscript and approved its final version.

\section{Acknowledgements}

The authors would like to thank Mr. Akiff Manji and Ms. Shadi Mahmoodi for their assistance with tissue collection. These studies were performed with funding from the American Heart Association (0635234 N), Canadian Diabetes Association (OG-2-08-2600-SC), Heart and Stroke Foundation of BC and the Yukon and the Michael Smith Foundation for Health Research (Cl$\mathrm{SCH}-01423(07-01))$. SMC is the Canada Research Chair in the Genetics of Obesity and Diabetes and is a Career Investigator of the Michael Smith Foundation for Health Research.

\section{Author details}

${ }^{1}$ Department of Cellular and Physiological Sciences, Life Sciences Institute, University of British Columbia, Vancouver, Canada. ${ }^{2}$ Department of Surgery, University of British Columbia, Vancouver, Canada.

Received: 28 August 2012 Accepted: 21 February 2013

Published: 25 February 2013

\section{References}

1. Danaei G, Finucane MM, Lu Y, Singh GM, Cowan MJ, Paciorek CJ, Lin JK, Farzadfar F, Khang YH, Stevens GA, et al: National, regional, and global trends in fasting plasma glucose and diabetes prevalence since, systematic analysis of health examination surveys and epidemiological studies with 370 country-years and 2.7 million participants. Lancet 1980 378(9785):31-40

2. Forsen T, Eriksson J, Tuomilehto J, Reunanen A, Osmond C, Barker D: The fetal and childhood growth of persons who develop type 2 diabetes. Ann Intern Med 2000, 133:176-182.

3. Florez JC: Clinical review: the genetics of type 2 diabetes: a realistic appraisal in 2008. J Clin Endocrinol Metab 2008, 93(12):4633-4642.

4. McCarthy MI: Genomics, type 2 diabetes, and obesity. N Engl J Med 2010 363(24):2339-2350

5. O'Rahilly S: Human genetics illuminates the paths to metabolic disease. Nature 2009, 462(7271):307-314.
6. Florez JC: Newly identified loci highlight beta cell dysfunction as a key cause of type 2 diabetes: where are the insulin resistance genes? Diabetologia 2008, 51(7):1100-1110.

7. O'Rahilly S, Barroso I, Wareham NJ: Genetic factors in type 2 diabetes: the end of the beginning? Science 2005, 307(5708):370-373.

8. Dina C, Meyre D, Gallina S, Durand E, Korner A, Jacobson P, Carlsson LM Kiess W, Vatin V, Lecoeur C, et al: Variation in FTO contributes to childhood obesity and severe adult obesity. Nat Genet 2007, 39(6):724-726

9. Sladek R, Rocheleau G, Rung J, Dina C, Shen L, Serre D, Boutin P, Vincent D, Belisle A, Hadjadj S, et al: A genome-wide association study identifies novel risk loci for type 2 diabetes. Nature 2007, 445(7130):881-885.

10. Saxena R, Voight BF, Lyssenko V, Burtt NP, de Bakker PI, Chen H, Roix JJ, Kathiresan S, Hirschhorn JN, Daly MJ, et al: Genome-wide association analysis identifies loci for type 2 diabetes and triglyceride levels. Science 2007, 316(5829):1336-1341.

11. Zeggini $E$, Weedon MN, Lindgren CM, Frayling TM, Elliott $K S$, Lango $H$, Timpson NJ, Perry JR, Rayner NW, Freathy RM, et al: Replication of genomewide association signals in U.K. Samples reveals risk loci for type 2 diabetes. Science 2007, 316(5829):1331-1336.

12. Scott LJ, Mohlke KL, Bonnycastle LL, Willer CJ, Li Y, Duren WL, Erdos MR, Stringham HM, Chines PS, Jackson AU, et al: A genome-wide association study of type 2 diabetes in Finns detects multiple susceptibility variants. Science 2007, 316(5829):1341-1345.

13. Steinthorsdottir $V$, Thorleifsson $G$, Reynisdottir I, Benediktsson R, Jonsdottir T, Walters GB, Styrkarsdottir U, Gretarsdottir S, Emilsson V, Ghosh S, et al: $A$ variant in CDKAL1 influences insulin response and risk of type 2 diabetes. Nat Genet 2007, 39(6):770-775.

14. Zeggini E, Scott LJ, Saxena R, Voight BF, Marchini JL, Hu T, de Bakker PI, Abecasis GR, Almgren P, Andersen G, et al: Meta-analysis of genome-wide association data and large-scale replication identifies additional susceptibility loci for type 2 diabetes. Nat Genet 2008, 40(5):638-645.

15. Bouatia-Naji N, Bonnefond A, Cavalcanti-Proenca C, Sparso T, Holmkvist J, Marchand M, Delplanque J, Lobbens S, Rocheleau G, Durand E, et al: A variant near MTNR1B is associated with increased fasting plasma glucose levels and type 2 diabetes risk. Nat Genet 2009, 41:89-94.

16. Altshuler D, Hirschhorn JN, Klannemark M, Lindgren CM, Vohl MC, Nemesh J, Lane CR, Schaffner SF, Bolk S, Brewer C, et al: The common PPARgamma Pro12Ala polymorphism is associated with decreased risk of type 2 diabetes. Nat Genet 2000, 26(1):76-80.

17. Gloyn AL, Weedon MN, Owen KR, Turner MJ, Knight BA, Hitman G, Walker M, Levy JC, Sampson M, Halford S, et al: Large-scale association studies of variants in genes encoding the pancreatic beta-cell KATP channel subunits Kir6.2 (KCNJ11) and SUR1 (ABCC8) confirm that the KCNJ11 E23K variant is associated with type 2 diabetes. Diabetes 2003, 52(2):568-572.

18. Morris AP, Voight BF, Teslovich TM, Ferreira T, Segre AV, Steinthorsdottir V, Strawbridge RJ, Khan $\mathrm{H}$, Grallert $\mathrm{H}$, Mahajan A, et al: Large-scale association analysis provides insights into the genetic architecture and pathophysiology of type 2 diabetes. Nat Genet 2012, 44(9):981-990.

19. Grant SF, Thorleifsson G, Reynisdottir I, Benediktsson R, Manolescu A, Sainz J, Helgason A, Stefansson H, Emilsson V, Helgadottir A, et al: Variant of transcription factor 7-like 2 (TCF7L2) gene confers risk of type 2 diabetes. Nat Genet 2006, 38(3):320-323.

20. Smith U: TCF7L2 and type 2 diabetes-we WNT to know. Diabetologia 2007, 50(1):5-7.

21. Fakhrai-Rad H, Nikoshkov A, Kamel A, Fernstrom M, Zierath JR, Norgren S, Luthman H, Galli J: Insulin-degrading enzyme identified as a candidate diabetes susceptibility gene in GK rats. Hum Mol Genet 2000, 9(14):2149-2158.

22. Farris W, Mansourian S, Chang Y, Lindsley L, Eckman EA, Frosch MP, Eckman CB, Tanzi RE, Selkoe DJ, Guenette S: Insulin-degrading enzyme regulates the levels of insulin, amyloid beta-protein, and the beta-amyloid precursor protein intracellular domain in vivo. Proc Natl Acad Sci USA 2003, 100(7):4162-4167.

23. Florez JC, Wiltshire S, Agapakis CM, Burtt NP, de Bakker PI, Almgren P, Bengtsson Bostrom K, Tuomi T, Gaudet D, Daly MJ, et al: High-density haplotype structure and association testing of the insulin-degrading enzyme (IDE) gene with type 2 diabetes in 4,206 people. Diabetes 2006, 55(1):128-135

24. Groves CJ, Wiltshire S, Smedley D, Owen KR, Frayling TM, Walker M, Hitman GA, Levy JC, O'Rahilly S, Menzel S, et al: Association and haplotype analysis of the insulin-degrading enzyme (IDE) gene, a strong positional and 
biological candidate for type 2 diabetes susceptibility. Diabetes 2003, 52(5):1300-1305

25. Gu HF, Efendic S, Nordman S, Ostenson CG, Brismar K, Brookes AJ, Prince JA: Quantitative trait loci near the insulin-degrading enzyme (IDE) gene contribute to variation in plasma insulin levels. Diabetes 2004, 53(8):2137-2142.

26. Karamohamed S, Demissie S, Volcjak J, Liu C, Heard-Costa N, Liu J, Shoemaker CM, Panhuysen Cl, Meigs JB, Wilson P, et al: Polymorphisms in the insulin-degrading enzyme gene are associated with type 2 diabetes in men from the NHLBI Framingham Heart Study. Diabetes 2003, 52(6):1562-1567.

27. Nicolson TJ, Bellomo EA, Wijesekara N, Loder MK, Baldwin JM, Gyulkhandanyan AV, Koshkin V, Tarasov Al, Carzaniga R, Kronenberger K, et al: Insulin storage and glucose homeostasis in mice null for the granule zinc transporter ZnT8 and studies of the type 2 diabetesassociated variants. Diabetes 2009, 58(9):2070-2083.

28. Pound LD, Sarkar SA, Benninger RK, Wang Y, Suwanichkul A, Shadoan MK, Printz RL, Oeser JK, Lee CE, Piston DW, et al: Deletion of the mouse Slc30a8 gene encoding zinc transporter- 8 results in impaired insulin secretion. Biochem J 2009, 421(3):371-376.

29. Wijesekara N, Dai FF, Hardy AB, Giglou PR, Bhattacharjee A, Koshkin V, Chimienti F, Gaisano HY, Rutter GA, Wheeler MB: Beta cell-specific Znt8 deletion in mice causes marked defects in insulin processing, crystallisation and secretion. Diabetologia 2010, 53(8):1656-1668.

30. Christiansen J, Kolte AM, Hansen TO, Nielsen FC: IGF2 mRNA-binding protein 2: biological function and putative role in type 2 diabetes. $J \mathrm{Mol}$ Endocrinol 2009, 43(5):187-195.

31. Kim W, Shin YK, Kim BJ, Egan JM: Notch signaling in pancreatic endocrine cell and diabetes. Biochem Biophys Res Commun 2010, 392(3):247-251.

32. Dror V, Nguyen V, Walia P, Kalynyak TB, Hill JA, Johnson JD: Notch signalling suppresses apoptosis in adult human and mouse pancreatic islet cells. Diabetologia 2007, 50(12):2504-2515.

33. Yamagata K, Senokuchi T, Lu M, Takemoto M, Fazlul Karim M, Go C, Sato Y, Hatta M, Yoshizawa T, Araki E, et al: Voltage-gated K + channel KCNQ1 regulates insulin secretion in MIN6 beta-cell line. Biochem Biophys Res Commun 2011, 407(3):620-625.

34. Poitout V, Robertson RP: Glucolipotoxicity: fuel excess and beta-cell dysfunction. Endocr Rev 2008, 29(3):351-366.

35. Shalev A, Pise-Masison CA, Radonovich M, Hoffmann SC, Hirshberg B, Brady JN, Harlan DM: Oligonucleotide microarray analysis of intact human pancreatic islets: identification of glucose-responsive genes and a highly regulated TGFbeta signaling pathway. Endocrinology 2002, 143(9):3695-3698.

36. Su Al, Cooke MP, Ching KA, Hakak Y, Walker JR, Wiltshire T, Orth AP, Vega $R G$, Sapinoso LM, Mogrich A, et al: Large-scale analysis of the human and mouse transcriptomes. Proc Natl Acad Sci USA 2002, 99(7):4465-4470.

37. Yoganathan P, Karunakaran S, Ho MM, Clee SM: Nutritional regulation of genome-wide association obesity genes in a tissue-dependent manner. Nutr Metab (Lond) 2012, 9(1):65.

38. Lam TK: Neuronal regulation of homeostasis by nutrient sensing. Nat Med 2010, 16(4):392-395.

39. Paranjape SA, Chan O, Zhu W, Horblitt AM, Grillo CA, Wilson S, Reagan L, Sherwin RS: Chronic reduction of insulin receptors in the ventromedial hypothalamus produces glucose intolerance and islet dysfunction in the absence of weight gain. Am J Physiol Endocrinol Metab 2011, 301(5):E978-E983.

40. Xu Y, Berglund ED, Sohn JW, Holland WL, Chuang JC, Fukuda M, Rossi J, Williams KW, Jones JE, Zigman JM, et al: 5-HT2CRs expressed by proopiomelanocortin neurons regulate insulin sensitivity in liver. Nat Neurosci 2010, 13(12):1457-1459.

41. Mountjoy PD, Rutter GA: Glucose sensing by hypothalamic neurones and pancreatic islet cells: AMPle evidence for common mechanisms? Exp Physiol 2007, 92(2):311-319.

42. Nakajima T, Fujino S, Nakanishi G, Kim YS, Jetten AM: TIP27: a novel repressor of the nuclear orphan receptor TAK1/TR4. Nucleic Acids Res 2004, 32(14):4194-4204.

43. Kim E, Ma WL, Lin DL, Inui S, Chen YL, Chang C: TR4 orphan nuclear receptor functions as an apoptosis modulator via regulation of $\mathrm{BCl}-2$ gene expression. Biochem Biophys Res Commun 2007, 361(2):323-328.

44. Lee YF, Liu S, Liu NC, Wang RS, Chen LM, Lin WJ, Ting HJ, Ho HC, Li G, Puzas EJ, et al: Premature aging with impaired oxidative stress defense in mice lacking TR4. Am J Physiol Endocrinol Metab 2011, 301(1):E91-E98.
45. Liu S, Lee YF, Chou S, Uno H, Li G, Brookes P, Massett MP, Wu Q, Chen LM, Chang C: Mice lacking TR4 nuclear receptor develop mitochondrial myopathy with deficiency in complex I. Mol Endocrinol 2011, 25(8):1301-1310.

46. Kang HS, Okamoto K, Kim YS, Takeda Y, Bortner CD, Dang H, Wada T, Xie W, Yang XP, Liao G, et al: Nuclear orphan receptor TAK1/TR4-deficient mice are protected against obesity-linked inflammation, hepatic steatosis, and insulin resistance. Diabetes 2011, 60(1):177-188.

47. Grarup N, Andersen G, Krarup NT, Albrechtsen A, Schmitz O, Jorgensen T, Borch-Johnsen $\mathrm{K}$, Hansen T, Pedersen O: Association testing of novel type 2 diabetes risk-alleles in the JAZF1, CDC123/CAMK1D, TSPAN8, THADA, ADAMTS9, and NOTCH2 loci with insulin release, insulin sensitivity and obesity in a population-based sample of 4,516 glucose-tolerant middleaged Danes. Diabetes 2008, 57:2534-2540.

48. Staiger H, Machicao F, Kantartzis K, Schafer SA, Kirchhoff K, Guthoff M, Silbernagel G, Stefan N, Fritsche A, Haring HU: Novel meta-analysis-derived type 2 diabetes risk loci do not determine prediabetic phenotypes. PLoS One 2008, 3(8):e3019.

49. Boesgaard TW, Gjesing AP, Grarup N, Rutanen J, Jansson PA, Hribal ML, Sesti $\mathrm{G}$, Fritsche A, Stefan N, Staiger $\mathrm{H}$, et al: Variant near ADAMTS9 known to associate with type 2 diabetes is related to insulin resistance in offspring of type 2 diabetes patients-EUGENE2 study. PLoS One 2009, 4(9):e7236.

50. Simonis-Bik AM, Nijpels G, van Haeften TW, Houwing-Duistermaat JJ, Boomsma DI, Reiling E, van Hove EC, Diamant M, Kramer MH, Heine RJ, et al: Gene variants in the novel type 2 diabetes loci CDC123/CAMK1D, THADA, ADAMTS9, BCL11A, and MTNR1B affect different aspects of pancreatic beta-cell function. Diabetes 2010, 59(1):293-301.

51. Marselli L, Thorne J, Dahiya S, Sgroi DC, Sharma A, Bonner-Weir S, Marchetti P, Weir GC: Gene expression profiles of Beta-cell enriched tissue obtained by laser capture microdissection from subjects with type 2 diabetes. PLoS One 2010, 5(7):e11499.

52. Vangipurapu J, Stancakova A, Pihlajamaki J, Kuulasmaa TM, Kuulasmaa T, Paananen J, Kuusisto J, Ferrannini E, Laakso M: Association of indices of liver and adipocyte insulin resistance with 19 confirmed susceptibility loci for type 2 diabetes in 6,733 non-diabetic Finnish men. Diabetologia 2011, 54(3):563-571.

53. Taneera J, Lang S, Sharma A, Fadista J, Zhou Y, Ahlqvist E, Jonsson A, Lyssenko V, Vikman $P$, Hansson $O$, et al: A systems genetics approach identifies genes and pathways for type 2 diabetes in human islets. Cell Metab 2012, 16(1):122-134

54. Voight BF, Scott LJ, Steinthorsdottir V, Morris AP, Dina C, Welch RP, Zeggin E, Huth C, Aulchenko YS, Thorleifsson G, et al: Twelve type 2 diabetes susceptibility loci identified through large-scale association analysis. Nat Genet 2010, 42(7):579-589.

55. Koo BH, Coe DM, Dixon LJ, Somerville RP, Nelson CM, Wang LW, Young ME, Lindner DJ, Apte SS: ADAMTS9 is a cell-autonomously acting, antiangiogenic metalloprotease expressed by microvascular endothelial cells. Am J Pathol 2010, 176(3):1494-1504.

56. Yoshina S, Sakaki K, Yonezumi-Hayashi A, Gengyo-Ando K, Inoue H, lino Y, Mitani S: Identification of a novel ADAMTS9/GON-1 function for protein transport from the ER to the Golgi. Mol Biol Cell 2012, 23(9):1728-1741.

57. Stancakova A, Kuulasmaa T, Paananen J, Jackson AU, Bonnycastle LL, Collins FS, Boehnke M, Kuusisto J, Laakso M: Association of 18 confirmed susceptibility loci for type 2 diabetes with indices of insulin release, proinsulin conversion, and insulin sensitivity in 5,327 nondiabetic Finnish men. Diabetes 2009, 58(9):2129-2136.

58. Richards OC, Raines SM, Attie AD: The role of blood vessels, endothelial cells, and vascular pericytes in insulin secretion and peripheral insulin action. Endocr Rev 2010, 31(3):343-363.

59. Raines SM, Richards OC, Schneider LR, Schueler KL, Rabaglia ME, Oler AT, Stapleton DS, Genove G, Dawson JA, Betsholtz C, et al: Loss of PDGF-B activity increases hepatic vascular permeability and enhances insulin sensitivity. Am J Physiol Endocrinol Metab 2011, 301(3):E517-E526.

60. Marfil V, Moya M, Pierreux CE, Castell JV, Lemaigre FP, Real FX, Bort R: Interaction between Hhex and SOX13 modulates Wnt/TCF activity. J Biol Chem 2010, 285(8):5726-5737.

61. Hunter MP, Wilson CM, Jiang X, Cong R, Vasavada H, Kaestner KH, Bogue $\mathrm{CW}$ : The homeobox gene Hhex is essential for proper hepatoblast differentiation and bile duct morphogenesis. Dev Biol 2007, 308(2):355-367.

62. Staiger H, Machicao F, Stefan N, Tschritter O, Thamer C, Kantartzis K, Schafer SA, Kirchhoff K, Fritsche A, Haring HU: Polymorphisms within novel risk 
loci for type 2 diabetes determine beta-cell function. PLOS One 2007, 2(9):e832.

63. Pascoe L, Tura A, Patel SK, Ibrahim IM, Ferrannini E, Zeggini E, Weedon MN Mari A, Hattersley AT, McCarthy Ml, et al: Common variants of the novel type 2 diabetes genes CDKAL1 and HHEX/IDE are associated with decreased pancreatic beta-cell function. Diabetes 2007, 56(12):3101-3104.

64. Pivovarova O, Nikiforova VJ, Pfeiffer AF, Rudovich N: The influence of genetic variations in HHEX gene on insulin metabolism in the German MESYBEPO cohort. Diabetes Metab Res Rev 2009, 25(2):156-162.

65. Rosengren AH, Braun M, Mahdi T, Andersson SA, Travers ME, Shigeto M, Zhang E, Almgren P, Ladenvall C, Axelsson AS, et al: Reduced insulin exocytosis in human pancreatic beta-cells with gene variants linked to type 2 diabetes. Diabetes 2012, 61(7):1726-1733.

66. Kirchhoff K, Machicao F, Haupt A, Schafer SA, Tschritter O, Staiger H, Stefan $\mathrm{N}$, Haring HU, Fritsche A: Polymorphisms in the TCF7L2, CDKAL1 and SLC30A8 genes are associated with impaired proinsulin conversion. Diabetologia 2008, 51(4):597-601.

67. Groenewoud MJ, Dekker JM, Fritsche A, Reiling E, Nijpels G, Heine RJ, Maassen JA, Machicao F, Schafer SA, Haring HU, et al: Variants of CDKAL1 and IGF2BP2 affect first-phase insulin secretion during hyperglycaemic clamps. Diabetologia 2008, 51(9):1659-1663.

68. Rippe V, Drieschner N, Meiboom M, Murua Escobar H, Bonk U, Belge G, Bullerdiek J: Identification of a gene rearranged by 2 p21 aberrations in thyroid adenomas. Oncogene 2003, 22(38):6111-6114.

69. Cerretti DP, DuBose RF, Black RA, Nelson N: Isolation of two novel metalloproteinase-disintegrin (ADAM) CDNAs that show testis-specific gene expression. Biochem Biophys Res Commun 1999, 263(3):810-815.

70. Wei FY, Tomizawa K: Functional loss of Cdkal1, a novel tRNA modification enzyme, causes the development of type 2 diabetes. Endocr J 2011, 58(10):819-825.

71. Ohara-Imaizumi M, Yoshida M, Aoyagi K, Saito T, Okamura T, Takenaka H, Akimoto Y, Nakamichi Y, Takanashi-Yanobu R, Nishiwaki C, et al: Deletion of CDKAL1 affects mitochondrial ATP generation and first-phase insulin exocytosis. PLoS One 2010, 5(12):e15553.

72. Wei FY, Suzuki T, Watanabe S, Kimura S, Kaitsuka T, Fujimura A, Matsui H, Atta M, Michiue H, Fontecave M, et al: Deficit of tRNA(Lys) modification by Cdkal1 causes the development of type 2 diabetes in mice. J Clin Invest 2011, 121(9):3598-3608.

73. Steil GM, Trivedi N, Jonas JC, Hasenkamp WM, Sharma A, Bonner-Weir S, Weir GC: Adaptation of beta-cell mass to substrate oversupply: enhanced function with normal gene expression. Am J Physiol Endocrinol Metab 2001, 280(5):E788-796.

74. Stickens D, Zak BM, Rougier N, Esko JD, Werb Z: Mice deficient in Ext2 lack heparan sulfate and develop exostoses. Development 2005, 132(22):5055-5068

75. Inatani M, Yamaguchi $Y$ : Gene expression of EXT1 and EXT2 during mouse brain development. Brain Res Dev Brain Res 2003, 141(1-2):129-136.

76. Carmon KS, Lin Q, Gong X, Thomas A, Liu Q: LGR5 Interacts and cointernalizes with Wnt receptors to modulate Wnt/beta-catenin signaling. Mol Cell Biol 2012, 32(11):2054-2064

77. Yan KS, Chia LA, Li X, Ootani A, Su J, Lee JY, Su N, Luo Y, Heilshorn SC, Amieva MR, et al: The intestinal stem cell markers Bmi1 and Lgr5 identify two functionally distinct populations. Proc Natl Acad Sci USA 2012, 109(2):466-471.

78. Gesierich S, Paret C, Hildebrand D, Weitz J, Zgraggen K, Schmitz-Winnenthal FH, Horejsi V, Yoshie O, Herlyn D, Ashman LK, et al: Colocalization of the tetraspanins, CO-029 and CD151, with integrins in human pancreatic adenocarcinoma: impact on cell motility. Clin Cancer Res 2005, 11(8):2840-2852.

79. Champy MF, Le Voci L, Selloum M, Peterson LB, Cumiskey AM, Blom D: Reduced body weight in male Tspan8-deficient mice. Int J Obes (Lond) 2011, 35(4):605-617.

80. Sharma NK, Langberg KA, Mondal AK, Elbein SC, Das SK: Type 2 diabetes (T2D) associated polymorphisms regulate expression of adjacent transcripts in transformed lymphocytes, adipose, and muscle from Caucasian and African-American subjects. J Clin Endocrinol Metab 2011, 96(2):E394-403.

81. Fu J, Wolfs MG, Deelen P, Westra HJ, Fehrmann RS, Te Meerman GJ, Buurman WA, Rensen SS, Groen HJ, Weersma RK, et al: Unraveling the regulatory mechanisms underlying tissue-dependent genetic variation of gene expression. PLoS Genet 2012, 8(1):e1002431.
82. Nica AC, Parts L, Glass D, Nisbet J, Barrett A, Sekowska M, Travers M, Potter S, Grundberg E, Small K, et al: The architecture of gene regulatory variation across multiple human tissues: the MuTHER study. PLOS Genet 2011, 7(2):e1002003.

83. Qi L, Liang J: Interactions between genetic factors that predict diabetes and dietary factors that ultimately impact on risk of diabetes. Curr Opin Lipidol 2010, 21(1):31-37.

84. Maston GA, Evans SK, Green MR: Transcriptional regulatory elements in the human genome. Annu Rev Genomics Hum Genet 2006, 7:29-59.

85. Salvalaggio PR, Deng S, Ariyan CE, Millet I, Zawalich WS, Basadonna GP, Rothstein DM: Islet filtration: a simple and rapid new purification procedure that avoids ficoll and improves islet mass and function. Transplantation 2002, 74(6):877-879.

86. Feise RJ: Do multiple outcome measures require $p$-value adjustment? BMC Med Res Methodol 2002, 2:8.

87. Yuan JS, Reed A, Chen F, Stewart CN Jr: Statistical analysis of real-time PCR data. BMC Bioinformatics 2006, 7:85

doi:10.1186/1471-2156-14-10

Cite this article as: Ho et al:: Diabetes genes identified by genome-wide association studies are regulated in mice by nutritional factors in metabolically relevant tissues and by glucose concentrations in islets. BMC Genetics 2013 14:10

\section{Submit your next manuscript to BioMed Central and take full advantage of:}

- Convenient online submission

- Thorough peer review

- No space constraints or color figure charges

- Immediate publication on acceptance

- Inclusion in PubMed, CAS, Scopus and Google Scholar

- Research which is freely available for redistribution

Submit your manuscript at www.biomedcentral.com/submit
C) Biomed Central 